\title{
PENGARUH HARGA KOMPETITIF, PROMOSI DAN \\ LOKASI TERHADAP KEPUTUSAN PEMBELIAN PADA KONSUMEN CV INTEGRITY PANGKALPINANG
}

\author{
Deri Kusmadeni \\ STIKES Abdi Nusa Pangkalpinang, Bangka Belitung, Indonesia \\ derikusma83@gmail.com
}

\begin{abstract}
ABSTRACK
General in consumers follow a process or stage in decision making, there are five stages, namely: problem recognition, information disbursement, alternative evaluation, purchasing decisions and pacapelian buying behavior. Price is what consumers (buyers) have to get for a product, promotion is planning, implementing, and controlling communication from an organization to consumers and other targets. The function of promotion in the marketing mix is to achieve various objectives of communication with each consumer. Location is a marketing mix tool that includes various activities carried out by the company to make products available and available to customers / targets.

This study purpose to determine the effect of simultaneous competitive prices, promotions and locations on purchasing decisions, the effect of partial competitive prices, promotions and locations on customer satisfaction.

The data analysis used in this study is multiple regression analysis, the coefficient of determination $\left(R^{2}\right)$ is 0.616 , which means that $61.6 \%$ of the variation in purchasing decisions can be explained by competitive prices, promotions and location, while $38.4 \%$ comes from factors others not examined in this study. The results of the $F$ test obtained a calculated $F$ value of 51.319 greater than $F$ table 3.091 or the significance of 0,000 $<\alpha(0.05)$, thus the hypothesis states that the competitive price variable, promotion and location together influence the purchasing decision. Based on the $t$ test that the competitive price variable, promotion and location have an influence on purchasing decisions

Keywords: purchasing decisions, competitive prices, promotions and location
\end{abstract}

\section{PENDAHULUAN}

Persaingan bisnis yang semakin ketat seperti saat ini menuntut perusahaan untuk semakin gencar dalam pemasarannya untuk menarik dan mempertahankan konsumennya. Hal ini menuntut perusahaan untuk semakin kreatif dalam menjalankan kegiatan usahanya. Era ini ditandai dengan semakin berkembangnya berbagai produk maupun jasa yang disertai inovasi baru. Berbagai upaya dilakukan oleh perusahaan untuk meningkatkan penjualan perusahaan serta memuaskan kebutuhan pelanggannya. Menyadari hal itu, jelas 
bahwa pemasaran merupakan salah satu kegiatan pokok yang dilakukan perusahaan untuk mempertahankan kelangsungan hidupnya untuk berkembang dan mendapatkan laba serta memperkuat posisi dalam menghadapi perusahaan pesaing. (David,2006:78)

Percetakan adalah sebuah proses industri (baik dilakukan oleh industri berskala kecil maupun besar) untuk memproduksi secara massal tulisan dan gambar, terutama dengan tinta di atas kertas menggunakan sebuah mesin cetak. Percetakan juga merupakan sebuah bagian penting dalam penerbitan dan percetakan transaksi. Di samping itu, percetakan pun tidak hanya fokus pada cetak saja secara kasat mata, tetapi di sana mencakup berbagai tekhnik dan jenis kegiatan yang dilakukan, seperti desain, penempatan warna yang tepat, pengukuran jenis kertas, dan lain sebagainya.

CV Integrity. Percetakan Integrity merupakan percetakan pertama yang sudah cukup lama berdiri dengan sistem modern di Pangkalpinang yang tepatnya berada di kota Pangkalpinang. Tepatnya di Jl. Lembawai No. 12A, Pangkalpinang. Dengan nama perusahaan CV Integrity yang kini memiliki 4 Divisi antara lain : percetakan offset, digital offset, digital printing, dan creative design interior yang mana semuanya telah mampu dikembangkan.

CV Integrity yang berdiri sejak 14 Desember 2002, Setelah 5 tahun, tepatnya tahun 2007 CV Integrity mulai melakukan ekspansi menuju lokasi yang strategis dipinggir jalan besar dengan merekrut teman-teman terdekat sang pendiri. Dan hingga kini berkat kerja keras dan sistem yang telah dibangun telah memiliki 12 karyawan.

Ditahun 2018 terjadinya penurunan pendapatan di CV Integrity dikarenakan munculnya pesaing baru yang lokasinya berdekatan dengan CV Integrity, yaitu percetakan PEPS telah membuka percetakan yang letaknya berdekatan dengan CV Integrity . Hal ini menyebabkan konsumen dapat membandingkan produk sebelum memilih dan membeli produk yang sesuai dengan keinginan dan harapannya. Sehingga berdampak langsung pada tingkat penjualan produk di CV Integrity

Dengan berpegang pada apa yang telah penulis uraikan di atas, muka penulis akan membahas tentang : "Pengaruh Harga Kompetitif, Promosi dan Lokasi terhadap Keputusan Pembelian pada Konsumen CV Integrity Pangkalpinang”. 


\section{LANDASAN TEORI}

\section{Harga kompetitif}

Lamb, dkk (2008:70), harga adalah apa yang Harus diberikan oleh konsumen (pembeli) untuk mendapatkan suatu produk. Harga sering merupakan unsur yang paling fleksibel di antara keempat unsur bauran pemasaran. Selain itu, Walker, dkk (2008), menerapkan kebijakan harga rendah dibandingkan dengan pesaing dapat diciptakan, apabila perusahaan memiliki keunggulan bersaing pada biaya rendah (low cost). Demikian halnya pendapat Kotler (2008:65), bahwa penetapan harga dan persaingan harga merupakan masalah nomor satu yang dihadapi oleh para eksekutif pemasaran. Namun, banyak perusahaan tidak mampu menangani penetapan harga dengan baik.

\section{Promosi}

Strategi promosi adalah perencanaan, implementasi, dan pengendalian komunikasi dari suatu organisasi kepada para konsumen dan sasaran lainnya. Fungsi promosi dalam bauran pemasaran adalah untuk mencapai berbagai tujuan komunikasi dengan setiap konsumen. Cravens (2000), menjelaskan bahwa strategi promosi mencakup penentuan (1) tujuan komunikasi, (2) peranan komponen-komponen pembentuk bauran promosi, (3) anggaran promosi dan (4) strategi setiap komponen bauran. Komponen bauran promosi mencakup periklanan, penjualan perorangan, promosi penjualan dan hubungan masyarakat.

\section{Lokasi}

Menurut Kotler (2007:82) tempat, alat bauran pemasaran lainnya, termasuk berbagai kegiatan yang dilakukan perusahaan untuk membuat produk dapat diperoleh dan tersedia bagi pelanggan/ sasaran. Payne (2010:181) lokasi berkenaan dengan keputusan perusahaan mengenai dimana operasi dan stafnya akan ditempatkan. Pentingnya lokasi untuk jasa tergantung pada jenis dan tingkat interaksi yang terlibat.

Menurut Kasmir dan Jaffar (2007:166), mengemukakan bahwa pemilihan lokasi perlu mempertimbangkan hal-hal sebagai berikut :
a. Dekat dengan kawasan industry pabrik
b. Dekat dengan lokasi perkantoran
c. Dekat dengan lokasi keramaian atau pasar
d. Dekat dengan lokasi perumahan 


\section{Keputusan Pembelian}

Ada beberapa tipe perilaku keputusan dalam membeli. Semakin kompleks keputusan biasanya akan melibatkan semakin banyak pihak yang terkait dan semakin banyak pertimbangan. Empat jenis perilaku pembelian menurut Kotler (2010) antara lain:

1. Perilaku pembelian yang rumit Konsumen terlibat dalam perilaku pembelian yang rumit bila mereka sangat terlibat dalam pembelian dan sadar akan adanya perbedaan besar antarmerek.

2. Perilaku pembelian pengurangan ketidaknyamanan

Kadang-kadang konsumen sangat terlibat dalam pembelian namun melihat sedikit perbedaan antarmerek. Keterlibatan yang tinggi disadari oleh fakta bahwa pembelian tersebut mahal, jarang dilakukan, dan berisiko.

3. Perilaku pembelian karena kebiasaan

Banyak produk dibeli pada kondisi rendahnya keterlibatan konsumen dan tidak adanya perbedaan antarmerek yang signifikan.

4. Perilaku pembelian yang mencari variasi

Beberapa situasi pembelian ditandai oleh keterlibatan konsumen yang rendah tetapi perbedaan antarmerek signifikan. Dalam situasi ini, konsumen sering melakukan peralihan merek. Peralihan merek terjadi karena mencari variasi dan bukannya karena ketidakpuasan.

\section{Kerangka Pemikiran}

Kerangka pemiiran penelitian menggambarkan hubungan dari variabel independen, dalam hal ini adalan harga kompetitif $\left(\mathrm{X}_{1}\right)$, promosi $\left(\mathrm{X}_{2}\right)$, lokasi $\left(\mathrm{X}_{3}\right)$, terhadap variabel dependen yaitu keputusan pembelian (Y). Adapun kerangka pemikiran yang digunakan adalah sebagai berikut :

\section{Gambar 1}

\section{Kerangka Pemikiran Penelitian}

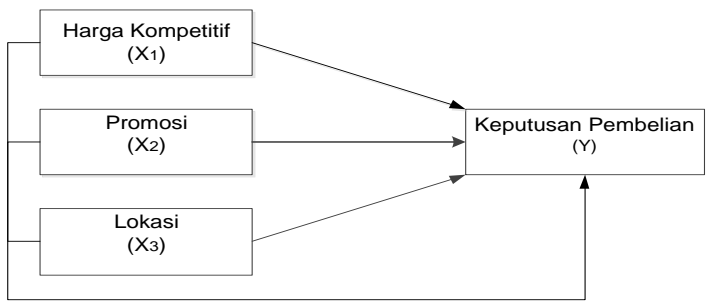

sumber diolah oleh : Peneliti 2020 


\section{Hipotesis}

Hipotesis merupakan jawaban sementara yang masih harus dibuktikan kebenarannya melalui penelitian. Hipotesis dalam penelitian ini adalah :

\section{Hipotesis 1}

Ho: Diduga harga kompetitif tidak berpengaruh positif dan signifikan terhadap keputusan pembelian.

$\mathrm{H}_{1}$ : Diduga harga kompetitif berpegaruh positif dan signifikan terhadap keputusan pembelian.

Hipotesis 2

Ho: Diduga Promosi tidak berpengaruh positif dan signifikan terhadap keputusan pembelian.

$\mathrm{H}_{1}$ : Diduga Promosi berpengaruh posistif dan signifikan terhadap keputusan pembelian.

Hipotesis 3

Ho: Diduga lokasi tidak berpengaruh positif dan signifikanterhadap keputusan pembelian.

$\mathrm{H}_{1}$ : Diduga lokasi positif dan signifikan terhadap keputusan pembelian.

\section{METODOLOGI PENELITIAN}

\section{Sampel}

Dalam penelitian ini peneliti tidak mengambil seluruh populasi yang ada di CV Integrity Pangkalpinang secara keseluruhan, maka dari itu peneliti akan mengambil sampel.

Sampel adalah bagian dari jumlah dan karakteristik yang dimiliki oleh populasi tersebut (Sugiyono, 2007) Sedangkan Supardi (2005) dalam mengungkapkan sampel penelitian adalah bagian dari populasi yang dijadikan subjek penelitian sebagai "wakil" dari para anggota populasi.

Jumlah sampel yang digunakan dalam penelitian ini mengikuti Paul Leddy dalam Arikunti (2006) bahwa untuk penelitian menggunakan teknik analisis SPSS mewajibkan bahwa sampel yang representatif penelitian minimal 100 orang responden. Teknik pengambilan sampel yang digunakan dalam penelitian ini adalah teknik pengambilan sampel yang digunakan adalah dengan teknik non probability sampling, yaitu teknik pengambilan sampel yang tidak memberi kesempatan yang sama bagi setiap unsur atau anggota populasi untuk di pilih sebagai sampel. Pengambilan sampel diambil dengan 
menggunakan metode accidental sampling (tidak sengaja), dimana peneliti menentukan sampelnya dari konsumen yang datang dan berebelanja di CV Integrity Pangkalpinang pada saat melakukan penelitian.

\section{Jenis Data}

Data yang dikumpulkan oleh peneliti dibagi atas dua jenis data, yaitu:

\section{A. Data Primer}

Merupakan data yang didapar dari sumber pertama, baik dari individu atau perusahaan.

Data Primer didapatkan melaluhi cara sebagai berikut :

a) Wawancara

Peneliti melakukan tanya jawab kepada responden maupun pihak-pihak lain yang terkait, untuk mendapatkan informasi penting yang berhubungan dengan objek penelitian.

b) Observasi

Peneliti melakukan pengamatan langsung terhadap kegiatan-kegiatan di CV Integrity Pangkalpinang dalam sistem proses kerja selama masa penelitian.

c) Kuesioner

Untuk mendapatkan data mengenai gambaran riel terhadap objek penelitian, peneliti menyebarkan daftar pertanyaan/pernyataan yang diajukan kepada pihak yan berhubungan langsung dengan masalah yang akan dditeliti oleh responden sendiri.

B. Data Skunder

Data skunder merupakan data yang diproleh melaluhi library research yakni dengan cara membaca dan mempelajari literatur- literatur, baik yang berupa buku-buku perpustakaan, catatan kuliah, serta referensi-referensi lain yang berhubungan dengan penelitian.

Dalam penelitian ini maka peneliti menggunakan data primer yaitu dengan menggunakan kuesioner yang merupakan suatu metode dengan cara memberikan sejumlah susunan pernyataan untuk memproleh jawaban dari responden, kuesioner ditunjukan kepada tamu yang datang, bertemu, dan menginap di CV Integrity Pangkalpinang. 


\section{Sumber Data}

Berikut adalah beberapa dalam analisis empiris Gujarati (2004) :

a. Data time series

Sering disebut juga dengan data runtut waktu yaitu merupakan rangkaian observasi pada suatu nilai yang diambil pada waktu yang berbeda-beda. Data data tersebut dikumpulkan secara berkala pada interval waktu tertentu, misalnya harian, mingguan, bulanan, atau tahunan. Meskipun data time series sering menimbulkan masalah dalam analisisnya, terutama masalah stationary. Secara singkat singkat data yang tidak stationer adalah data dimana nilai rata-rata dan variansnya tidak sistematis dalam kurun waktu tertentu.

b. Data Cross Section

Data cross section dalah data dari satu atau lebih variabel yang dikumpulkan dalam waktu yang sama, misalnya sensus penduduk. Data tipe ini juga mempunyai permaslahan lain yaitu masalah heterogenistas.

Dalam penelitian menggunakan jenis data cross section karena data yang dikumpulkan dengan menggunakan kuesioner dari responden lebih dari satu data seperti mengenai harga kompeitif, promosi dan lokasi terhadap keputusan pembelian sehingga metode yang digunakan yaitu metode pengumpulan data dengan cross section.

\section{Metode Pengumpulan Data}

Untuk mendapatkan data yang diperlukan dalam penulisan skripsi ini, peneliti mengadakan peneliti pada CV Integrity Pangkalpinang Provinsi Kepulauan Bangka Belitung. Dalam penelitian ini digunakan beberapa metode pengumpulan data, diantaranya sebagai berikut:

a. Kuesioner (data primer)

Yaitu berupa rangkaian pernyataan yang disusun secara sistematis dalam sebuah daftar pertanyaan kemudian diberikan kepada responden untuk diisi.

b. Dokumentasi (data skunder)

Yaitu pengumpulan data dan informasi yang diperoleh melaluhi dokumentasi / arsip yang ada pada intansi atau organisasi sehingga dapat dipelajari bagaimana gambaran umum penelitian. 


\section{PEMBAHASAN}

\section{Uji Validitas}

Suatu item Skor dikatakan valid bila $\mathrm{r}_{-}{ }_{\text {hitung }}>\mathrm{r}_{-}{ }_{\text {tabe }} \mathrm{l}$, sebaliknya jika $\mathrm{r}_{\text {-hitung }}<\mathrm{r}_{\text {-tabel }}$ maka suatu item Skor tersebut dikatakan tidak valid. Pada Peneliti ini responden dengan sampel sebanyak 100 orang, dengan $\alpha=0,05$ didapat $r_{\text {tabel }} 0,303$, artinya bila $r_{\text {hitung }}<r_{\text {tabel }}$ maka instrumen tersebut tidak valid dan apabila $r_{\text {hitung }}>r_{\text {tabel }}$, maka instrumen tersebut dapat digunakan (valid). dengan $\alpha=0,05$. Hasil untuk uji validitas menggunakan hitungan secara manual menggunakan bantuan aplikasi. SPSS Versi 21.

TABEL 1

HASIL UJI VALIDITAS VARIABEL $\left(\mathbf{X}_{1}\right)$

\begin{tabular}{|c|c|c|c|}
\hline Nomor Kueisoner & $\mathbf{r}_{\text {hitung }}$ & $\mathbf{r}_{\text {tabel }}$ & Keterangan \\
\hline 1 & 0,425 & 0,30 & Valid \\
\hline 2 & 0,409 & 0,30 & Valid \\
\hline 3 & 0,508 & 0,30 & Valid \\
\hline 4 & 0,498 & 0,30 & Valid \\
\hline 5 & 0,573 & 0,30 & Valid \\
\hline
\end{tabular}

Sumber: Data diolah Peneliti

Berdasarkan data tabel 1 tersebut diatas dapat diketahui bahwa nilai koefisien korelasi untuk uji validitas instrument variabel harga kompetitif $\left(\mathrm{X}_{1}\right)$ yang diperoleh butir skor jawaban item kuesioner, dari seluruh Skor bahwa menunjukan perbandingan $\mathrm{r}_{\text {-hitung }}$ lebih besar daripada $r-t_{a b e l}$, sehingga seluruh Skor dinyatakan valid. Hal ini dapat disimpulkan bahwa variabel harga kompetitif dapat dilanjutkan dengan pengujian regresi.

TABEL 2

HASIL UJI VALIDITAS VARIABEL $\left(\mathbf{X}_{2}\right)$

\begin{tabular}{|c|c|c|c|}
\hline Nomor Kueisoner & $\mathbf{r}_{\text {hitung }}$ & $\mathbf{r}_{\text {tabel }}$ & Keterangan \\
\hline 1 & 0,612 & 0,30 & Valid \\
\hline 2 & 0,416 & 0,30 & Valid \\
\hline 3 & 0,462 & 0,30 & Valid \\
\hline 4 & 0,471 & 0,30 & Valid \\
\hline
\end{tabular}

Sumber: Data diolah Peneliti 
Berdasarkan data yang tertera pada tabel 2 dapat diketahui bahwa nilai koefisien korelasi untuk uji validitas instrumen variabel Promosi $\left(\mathrm{X}_{2}\right)$ yang diperoleh diperoleh butir skor jawaban item kuesioner, dari seluruh Skor bahwa menunjukan perbandingan $\mathrm{r}_{\text {-hitung }}$ lebih besar daripada $r-t_{\text {abel}}$, sehingga seluruh Skor dinyatakan valid. Hal ini dapat disimpulkan bahwa variabel Promosi dapat dilanjutkan dengan pengujian regresi.

TABEL 3

UNTUK UJI VALIDITAS $\left(\mathbf{X}_{3}\right)$

\begin{tabular}{|c|c|c|c|}
\hline Nomor Kueisoner & $\mathbf{r}_{\text {hitung }}$ & $\mathbf{r}_{\text {tabel }}$ & Keterangan \\
\hline 1 & $0,4,80$ & 0,203 & Valid \\
\hline 2 & 0,378 & 0,203 & Valid \\
\hline 3 & 0,530 & 0,203 & Valid \\
\hline 4 & 0,421 & 0,203 & Valid \\
\hline & & & \\
\hline
\end{tabular}

Sumber: Data diolah Peneliti

Berdasarkan data yang tertera pada tabel 3 tersebut dapat diketahui bahwa nilai koefisien korelasi untuk uji validitas instrument variabel lokasi $\left(\mathrm{X}_{3}\right)$ yang diperoleh butir skor jawaban item kuesioner, dari seluruh Skor bahwa menunjukan perbandingan $\mathrm{r}_{\text {-hitung }}$ lebih besar daripada $r-t_{a b e l}$, sehingga seluruh Skor dinyatakan valid. Hal ini dapat disimpulkan bahwa variabel lokasi dapat dilanjutkan dengan pengujian regresi.

TABEL 4

HASIL UJI VALIDITAS VARIABEL (Y)

\begin{tabular}{|c|c|c|c|}
\hline Nomor Kueisoner & $\mathbf{r}_{\text {hitung }}$ & $\mathbf{r}_{\text {tabel }}$ & Keterangan \\
\hline 1 & 0,436 & 0,30 & Valid \\
\hline 2 & 0,536 & 0,30 & Valid \\
\hline 3 & 0,345 & 0,30 & Valid \\
\hline 4 & 0,419 & 0,30 & Valid \\
\hline 5 & 0,585 & 0,30 & Valid \\
\hline
\end{tabular}

Sumber: Data diolah Peneliti

Berdasarkan data yang tertera pada tabel 4 dapat diketahui bahwa nilai koefisien korelasi untuk uji validitas instrument variabel Kepuasan Pelanggan (Y) yang diperoleh 
butir skor jawaban item kuesioner, dari seluruh Skor bahwa menunjukan perbandingan rhitung lebih besar daripada $r-t_{a b e l}$, sehingga seluruh Skor dinyatakan valid. Hal ini dapat disimpulkan bahwa variabel keputusan pembelian dapat dilanjutkan dengan pengujian regresi.

\section{Uji Reliabilitas}

Suatu pengukuran dapat dikatakan reliabilitas apabila memiliki koefisien Cronbach Alpha lebih dari 0,60 (Sunyoto, 2011). Dari hasil uji reliabilitas variabel harga kompetitif $\left(\mathrm{X}_{1}\right)$, promosi $\left(\mathrm{X}_{2}\right)$, lokasi $\left(\mathrm{X}_{3}\right)$. Maka hasil uji reliabilitas variabel tersebut dapat dilihat pada tabel 4 sebagai berikut dibawah ini:

TABEL 5

KOEFISIEN RELIABILITAS VARIABEL

\begin{tabular}{|c|c|c|c|}
\hline No & Variabel & Koefisien Reliabilitas (Alpha) & $\begin{array}{c}\text { KETER } \\
\text { ANGAN }\end{array}$ \\
\hline 1 & Harga kompetitif & 0,822 & Reliable \\
\hline 2 & Promosi & 0,707 & Reliable \\
\hline 3 & Lokasi & 0,645 & Reliable \\
\hline 4 & Keputusan Pembelian & 0,684 & Reliable \\
\hline
\end{tabular}

Sumber: Data diolah Peneliti

Berdasarkan data pada tabel 5 Uji Reliabilitas tersebut menunjukkan bahwa masingmasing variabel yang digunakan dalam Peneliti ini memiliki nilai Cronbach's Alpha Based On Standardized Items $>0,60$, sehingga dapat dikatakan bahwa masing-masing variabel dari kuesioner adalah reliabel yang berarti kuesioner yang digunakan dalam Peneliti ini dapat dipercaya atau layak. Hal ini dapat disimpulkan bahwa seluruh variabel dalam Peneliti ini dapat dilanjutkan dengan pengujian regresi.

\section{Uji Normalitas}

Pengujian normalitas data, dilakukan dengan melihat hasil untuk distribusi standardized residual, dan dibuat grafik $Q-Q$ Plot. Untuk memperoleh hasil yang akurat, penghitungan dilakukan dengan program SPSS Versi 21 sehingga memenuhi persyaratan normalitas, dapat dilihat pada gambar berikut ini: 
GAMBAR 2

HASIL UJI NORMALITAS

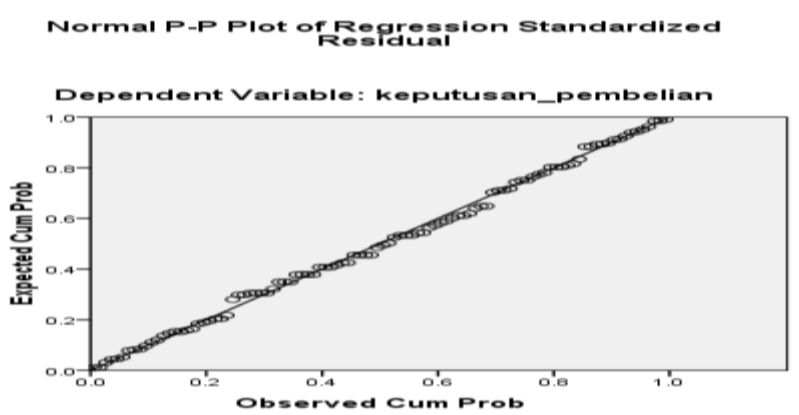

Berdasarkan gambar 1 diatas bahwa $Q-Q$ Plot Memperliatkan bahwa sebaran data pada chart tersebut terdapat korelasi yang kuat antara Standardized Residuals dengan Theoretical Quantiles sehingga memenuhi normalitas. Pola penyebaran titik - titik mendekati dan mengelilingi garis diagonal dapat ditarik kesimpulan, jika residual berasal dari distribusi noirmal, maka nilai - nilai sebaran data akan terletak di sekitar garis lurus (tidak terpencar jauh dari garis lurus), sehhingga dapat dinyatakan bahwa persyaatan normal.

\section{Uji Multikolineritas}

Uji multikolineritas dilakukan untuk mengetahui apabila variabel bebas yang diuji benar-benar bebas, jika nilai VIF yang diperoleh $<10$, maka dapat dikatakan bahwa tidak ada multicollinerity antara variabel bebas, cara yang digunakan adalah dengan menghitung tolerance dan VIF. Berdasarkan perhitungan menggunakan SPSS Versi 21 maka didapatkan hasil sebagai berikut.

TABEL 6

\section{KOEFESIEN MULTIKOLINEARITAS}

\begin{tabular}{|l|l|l|l|}
\hline \multicolumn{2}{|l|}{ Coefficients $^{\text {a }}$} \\
\hline \multirow{2}{*}{ Model } & \multicolumn{2}{|l|}{ Collinearity Statistics } \\
\cline { 2 - 4 } & Tolerance & VIF \\
\hline \multirow{2}{*}{1} & (Contant) & & \\
\cline { 2 - 4 } & Harga Kompetitif & 0,299 & 3,342 \\
\cline { 2 - 4 } & Promosi & 0,312 & 3,205 \\
\hline & Lokasi & 0,512 & 1,952 \\
\hline
\end{tabular}

Sumber: data diolah peneliti 
Dari data tabel diatas hasil perhitungan nilai variance inflation factor (VIF) menunjukan tidak ada satu variabel independen yang memiliki nilai VIF kurang dari 10. Jadi dapat disimpulkan bahwa tidak ada multikolinearitas antar variabel independen dalam model regresi.

\section{Persamaan Regresi}

Berdasarkan hasil perhitungan dengan menggunakan bantuan komputer pada Software Program JASP 0.9.2.0, Universiteit-van-amsterdam diperoleh hasil nilai persamaan regresi linear berganda antara variabel bebas $\mathrm{X}$, yaitu; Harga kompetitif $\left(\mathrm{X}_{1}\right)$, Promosi $\left(\mathrm{X}_{2}\right)$, Lokasi $\left(\mathrm{X}_{3}\right)$, dan Keputusan Pembelian (Y) pada konsumen CV Integrity Pangkalpinang. Sedangkan hasil perhitungan dapat dijelaskan dengan lampiran pada tabel sebagai berikut:

TABEL 7

HARGA KOMPETITIF $\left(\mathrm{X}_{1}\right)$, PROMOSI $\left(\mathrm{X}_{2}\right)$, LOKASI $\left(\mathrm{X}_{3}\right)$, KEPUTUSAN PEMBELIAN (Y)

\section{Coefesients}

\begin{tabular}{|c|c|c|c|c|c|}
\hline \multirow{2}{*}{ Model } & \multicolumn{2}{|c|}{ Unstandardized Coefficients } & Standardized Coefficients & & \\
\cline { 2 - 7 } & $\mathrm{B}$ & Std. Error & Beta & $\mathrm{t}$ & Sig. \\
\hline $\begin{array}{c}\text { (Constant) } \\
\text { Harga_Kom } \\
\text { petitif }\end{array}$ & 4.129 & .697 & & 5.924 & .000 \\
\cline { 2 - 7 } $\begin{array}{c}\text { Promosi } \\
\text { Lokasi }\end{array}$ & .325 & .055 & .369 & 5.886 & .000 \\
\cline { 2 - 7 } & .955 & .044 & & 3.018 & .003 \\
\hline
\end{tabular}

Berdasarkan pada tabel 7 pengaruh harga kompetitif, promosi dan lokasi terhadap keputusan pembelian pada CV Integrity pangkalpinang”. dapat dijelaskan sebagai berikut dibawah ini:

$Y=a+b_{1} X_{1}+b_{2} X_{2}+b_{3} X_{3}$

$\mathrm{Y}=4,129+0,325+0,179+0,955$

Sig $=(0.000)(0,003)(0,000)$ 
Berdasarkan hasil output SPSS Versi 21,tersebut tabel 7 diatas, angka-angka yang terdapat didalam kurung adalah merupakan besarnya nilai signifikan dari masing-masing variabel bebas, dimana koefisien regresi $<\alpha(0,05)$ berarti berpengaruh signifikan variabel (X terhadap Y) nilainya adalah positif, artinya hubungan tersebut dengan Keputusan Pembelian (Y) adalah searah, sehingga apabila variabel-variabel bebas yaitu; Harga kompetitif $\left(\mathrm{X}_{1}\right)$, Promosi $\left(\mathrm{X}_{2}\right)$ Lokasi $\left(\mathrm{X}_{3}\right)$, tersebut mengalami kenaikan, maka nilai variabel terikat juga akan mengalami kenaikan atau sebaliknya.

Sedangkan nilai Konstanta dan nilai koefisien dari masing-masing variabel $(\mathrm{X})$ dan Keputusan Pembelian (Y) dengan hasil persamaan tersebut sehingga dapat dijelaskan dengan uraian sebagai berikut:

1) Konstanta: 4,129 menyatakan bahwa jika tidak ada variabel Nilai-nilai konsumen dengan harga kompetitif $\left(\mathrm{X}_{1}\right)$, promosi $\left(\mathrm{X}_{2}\right)$, lokasi $\left(\mathrm{X}_{3}\right)$ maka keputusan pembelian $(\mathrm{Y})$ adalah 4,129 satuan.

2) Untuk harga kompetitif $\left(\mathrm{X}_{1}\right)$ : 0,325, artinya apabila variabel Nilai harga kompetitif 1 satuan maka akan meningkatkan keputusan pembelian sebesar 0,325 satuan.

3) Untuk promosi $\left(\mathrm{X}_{2}\right)$ : 0,179, artinya apabila variabel Promosi meningkat 1 satuan maka akan meningkatkan keputusan pembelian sebesar 0, 179 satuan.

4) Untuk lokasi $\left(\mathrm{X}_{3}\right)$ : 0,955, artinya apabila variabel Nilai lokasi meningkat 1 satuan, maka akan meningkatkan keputusan pembelian sebesar 0, 955 satuan.

\section{Koefesien Determinasi}

Berdasarkan hasil analisis Model Summary diperoleh angka (R) adalah sebesar 0,888, pada tabel 7 tersebut dibawah ini, dengan hasil angka tersebut meyatakan adanya pengaruh yang positif dan signifikan secara simultan antara variabel terikat dan variabel bebas, yaitu; variabel harga kompetitif $\left(\mathrm{X}_{1}\right)$, Promosi $\left(\mathrm{X}_{2}\right)$ dan lokasi $\left(\mathrm{X}_{3}\right)$ dengan nilai $\left(\mathrm{R}^{2}\right)$ sebesar $0,888^{\mathrm{a}}$ adjusted $r$-square, karena disesuaikan dengan jumlah variabel independen yang digunakan (lebih dari satu variabel) terlihat pada tabel 7 sebagai berikut: 
TABEL 8

KOEFISIEN DETERMINASI

Model Summary

\begin{tabular}{|c|c|r|r|r|}
\hline Model & $\mathrm{R}$ & R Square & Adjusted R Square & Std. Error of the Estimate \\
\hline 1 & $.942^{\mathrm{a}}$ & .888 & .885 & 1.280 \\
\hline
\end{tabular}

Berdasarkan pada tabel 8, tersebut diatas diperoleh koefisien determinasi (ajusted $r$ square) adalah sebesar 0, 888. Nilai ini dapat didefinisikan bahwa menjedi sebesar 88,8\% variabel Keputusan pembelian (Y) dapat dijelaskan oleh variabel Keputusan pembelian atribut variable harga kompetitif $\left(\mathrm{X}_{1}\right)$, promosi $\left(\mathrm{X}_{2}\right)$ dan lokasi $\left(\mathrm{X}_{3}\right)$ secara simultan/bersama-sama, sisanya sebesar $11,2 \%$ oleh variabel lain yang tidak dimasukkan dalam Peneliti ini.

Hal ini dapat disimpulkan bahwa terdapat pengaruh yang sangat kuat variabel harga kompetitif $\left(\mathrm{X}_{1}\right)$, Promosi $\left(\mathrm{X}_{2}\right)$ dan Lokasi $\left(\mathrm{X}_{3}\right)$ secara simultan terhadap Keputusan pembelian (Y) dengan perolehan total nilai sebesar $88,8 \%$.

TABEL 9

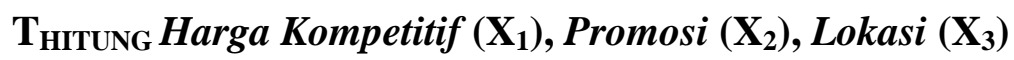

\section{Coeffisients}

\begin{tabular}{|c|c|c|c|c|c|}
\hline \multirow{2}{*}{ Model } & \multicolumn{2}{|c|}{ Unstandardized Coefficients } & Standardized Coefficients & & \\
\cline { 2 - 6 } & $\mathrm{B}$ & Std. Error & Beta & $\mathrm{t}$ & Sig. \\
\hline $\begin{array}{c}\text { (Constant) } \\
\text { Harga_Komp } \\
\text { etitif }\end{array}$ & 4.129 & .697 & & 5.924 & .000 \\
\cline { 2 - 6 } $\begin{array}{c}\text { Promosi } \\
\text { Lokasi }\end{array}$ & .179 & .055 & .369 & 5.886 & .000 \\
\cline { 2 - 6 } & .955 & .059 & .185 & 3.018 & .003 \\
\hline
\end{tabular}

Sumber: SPSS Versi 21 
Dari tabel 9, tersebut, bahwa terdapat output program SPSS Versi 21 berdasarkan hasil persamaan regresi dengan $t_{\text {hitung, }}$, sebesar 5,924 sedangkan $t_{\text {tabel }}$ dengan derajat bebas 92 pada $\alpha \alpha(0.05)$, sebesar 1,984, dengan demikian $\mathrm{t}_{\text {hitung }} 5,924>\mathrm{t}_{\text {tabel }}$ sebsar 1,984.

Adapun hasil tabel tersebut dengan uraian dan penjelasan sebagai berikut:

\section{a. Uji t Untuk $b_{1}$}

$$
\begin{aligned}
Y= & a+b_{1} X_{1} \\
Y= & 4.129+0,325 X_{1} \\
& (0.000)(0.000)
\end{aligned}
$$

Berdasarkan persamaan regresi secara parsial pada tabel diatas, terdapat nilai konstanta dari koefisien menyatakan bahwa variabel harga kompetitif $\left(\mathrm{X}_{1}\right)$ terdapat hubungan dengan keputusan pembelian (Y). Dalam persamaan regresi tersebut dapat dijelaskan sebagai beriku:

1) Konstanta sebesar 4.129, artinya menyatakan bahwa jika tidak ada harga kompetitif $\left(\mathrm{X}_{1}\right)$, maka keputusan pembelian (Y) pada konsumen CV Integrity Pangakalpinang adalah 4.129 satuan.

2) Untuk harga kompetitif sebesar 0,325, artinya apabila harga kompetitif meningkat sebesar 1 satuan, maka keputusan pembelian (Y) pada konsumen CV Integrity Pangakalpinang sebesar 0, 325 satuan.

Hasil output SPSS Versi 21terdapat variabel harga kompetitif $\left(\mathrm{X}_{1}\right)$ dengan $t_{\text {hitung }}$ Sebesar 5.886 dan nilai signifikan sebesar 0,000. Sedangkan dari df $t_{\text {tabel }} \alpha 0.05 t_{\text {tabel }}$ sebesar 1,984. Dengan nilai signifikan yang dihasilkan sebesar 0,000 dan signifikan $t_{\text {tabel }}$ dengan taraf $\alpha 0.05$, hasil ini dapat dilihat pada tabel 9 diatas dan $t_{\text {tabel }}$ pada lampiran akhir $b a b$, dengan perbandingan antara $t_{\text {hitung }}$ dengan $t_{\text {tabel }}$ dengan penyajian sebagai berikut:

1. Perbandingan $\left(\mathrm{t}_{\text {hitung }} 5.886\right)>\left(\mathrm{t}_{\text {tabel }} 1,984\right)$

2. Perbandingan nilai signifikan $(0,000<0,05)$

Berpedoman pada perbandingan nilai $\mathrm{t}_{\text {hitung }}$ output SPSS Versi 21 dan $\mathrm{t}_{\text {tabel }}$ dengan taraf $\alpha(0.05)$. Dengan hasil analisis perbandingan pembahasan tersebut diatas, maka dapat kita simpulkan bahwa hasil analisis dengan $\mathrm{H}_{0}$ ditolak dan $\mathrm{H}_{1}$ diterima. Dengan demikian harga kompetitif adanya arah hubungan yang positif keputusannya sangat jelas $\mathrm{H}_{0}$ ditolak dan $\mathrm{H}_{1}$ diterima. Hal ini menunjukkan dengan demikian variabel harga kompetitif mempunyai pengaruh yang signifikan terhadap keputusan pembelian pada konsumen CV Integrity Pangakalpinang. 


\section{b. Uji t Untuk $b_{2}$}

$$
\begin{aligned}
& Y=a+b_{2} X_{2} \\
& Y=4.129+0.179 X_{2} \\
& (0,000)(0.003)
\end{aligned}
$$

Berdasarkan persamaan regresi secara parsial pada tabel dan uraian diatas, terdapat nilai konstanta dari koefisien menyatakan bahwa variabel Promosi $\left(\mathrm{X}_{2}\right)$ terdapat hubungan dengan keputusan pembelian (Y). Dalam persamaan regresi tersebut dapat dijelaskan sebagai beriku:

1) Konstanta sebesar 4.129, artinya menyatakan bahwa jika tidak ada Promosi $\left(\mathrm{X}_{2}\right)$, maka keputusan pembelian (Y) pada CV Integrity Pangakalpinang adalah 4.129 satuan.

2) Untuk Promosi sebesar 0,179, artinya apabila Promosi meningkat sebesar 1 satuan, maka akan meningkatkan keputusan pembelian pada konsumen CV Integrity Pangakalpinang sebesar 0, 179 satuan.

Berdasarkan output SPSS Versi 21 diperoleh Promosi $\left(\mathrm{X}_{2}\right)$ dengan $\mathrm{t}_{\text {hitung }}$ Sebesar 3.018 dan nilai signifikan sebesar 0, 003. Sedangkan dari df $t_{\text {tabel }}$ pembilang (100) pada kolom (2) $\alpha 0.05 t_{\text {tabel }}$ sebesar 1, 984. Nilai signifikan yang dihasilkan sebesar 0, 003 dengan signifikan $t_{\text {tabel }}$ dengan taraf $\alpha(0.05)$, hasil ini dapat dilihat pada tabel 9 diatas. Hal ini akan dilakukan perbandingan antara $t_{\text {hitung }}$ dengan $t_{\text {tabel }}$ dengan uraian sebagai berikut:

1. Perbandingan $\left(\mathrm{t}_{\text {hitung }} 3,018\right)>\left(\mathrm{t}_{\text {tabel }} 1,984\right)$

2. Perbandingan nilai signifikan $(0,003<0,05)$

Berpedoman pada tabel $t_{\text {hitung }}$ output SPSS Versi 21 dan $t_{\text {tabel }}$ dengan taraf $\alpha(0.05)$. Hasil analisis perbandingan, maka dapat kita simpulakan bahwa hasil pembahasan tersebut diatas, dengan hasil $\mathrm{H}_{0}$ ditolak dan $\mathrm{H}_{2}$ diterima. Dengan demikian, Promosi dengan arah hubungan yang positif keputusannya sangat jelas $\mathrm{H}_{0}$ ditolak dan $\mathrm{H}_{2}$ diterima. Hal ini menunjukkan bahwa Promosi mempunyai pengaruh positif dan signifikan terhadap keputusan pembelian pada konsumen CV Inegrity Pangakalpinang.

\section{c. Uji t Untuk b3}

$$
\begin{aligned}
& Y=a+b_{3} X_{3} \\
& Y=4.129+0,955 X_{1}
\end{aligned}
$$

$$
(0.000) \quad(0.000)
$$

Berdasarkan persamaan regresi secara parsial pada tabel diatas, terdapat nilai konstanta dari koefisien menyatakan bahwa variabel loaksi $\left(\mathrm{X}_{3}\right)$ terdapat hubungan dengan 
keputusan pembelian (Y). Dalam persamaan regresi tersebut dapat dijelaskan sebagai beriku:

1) Konstanta sebesar 4.129, artinya menyatakan bahwa jika tidak ada promosi $\left(X_{3}\right)$, maka keputusan pembelian (Y) pada CV Integrity Pangakalpinang adalah 4.129.

2) Untuk lokasi sebesar 0,955, artinya apabila lokasi meningkat sebesar 1 satuan, maka akan meningkatkan keputusan pembelian pada konsumen CV Integrity Pangakalpinang sebesar 0,955 satuan.

Hasil output SPSS Versi 21 terdapat variabel lokasi $\left(\mathrm{X}_{3}\right)$ dengan $\mathrm{t}_{\text {hitung }}$ Sebesar 21.834 dan nilai signifikan sebesar 0,000 . Sedangkan dari df $t_{\text {tabel }} \alpha 0.05 t_{\text {tabel }}$ sebesar 1,984. Dengan nilai signifikan yang dihasilkan sebesar 0,000 dan signifikan $\mathrm{t}_{\text {tabel }}$ dengan taraf $\alpha$ 0.05, hasil ini dapat dilihat pada tabel 9 diatas dan $t_{\text {tabel }}$ pada lampiran akhir bab, dengan perbandingan antara $t_{\text {hitung }}$ dengan $t_{\text {tabel }}$ dengan uraian sebagai berikut:

1. Perbandingan ( $\left.\mathrm{t}_{\text {hitung }} 21,834\right)>\left(\mathrm{t}_{\text {tabel }} 1,984\right)$

2. Perbandingan nilai signifikan $(0,000<0,05)$

Berpedoman pada perbandingan nilai $\mathrm{t}_{\text {hitung }}$ output SPSS Versi 21 dan $\mathrm{t}_{\text {tabel }}$ dengan taraf $\alpha(0.05)$. Dengan hasil analisis perbandingan pembahasan tersebut diatas, maka dapat kita simpulkan bahwa hasil analisis dengan $\mathrm{H}_{0}$ ditolak dan $\mathrm{H}_{3}$ diterima. Dengan demikian lokasi dengan adanya arah hubungan yang positif keputusannya sangat jelas $\mathrm{H}_{0}$ ditolak dan $\mathrm{H}_{3}$ diterima. Hal ini menunjukkan dengan demikian variabel lokasi mempunyai pengaruh yang signifikan terhadap keputusan pembelian pada konsumen CV Integrity Pangakalpinang.

\section{Uji F}

Pengujian uji $\mathrm{F}$ yang dilakukan untuk secara simultan, adapun untuk hipotesis uji $\mathrm{F}$ yang dilakukan dengan uraian hipotesis sebagai berikut:

$\mathrm{H}_{0}$ : Tidak terdapat pengaruh harga kompetitif, promosi dan lokasi terhadap keputusan pembelian.

$\mathrm{H}_{6}$ : Terdapat pengaruh harga kompetitif, promosi dan lokasi terhadap keputusan pembelian.

Setelah dilakukan perhitungan dengan menggunakan software program SPSS Versi 21 terdapat hail uji F yaitu; output SPSS Versi 21 akan dijelaskan pada tabel sebagai berikut: 
TABEL 10

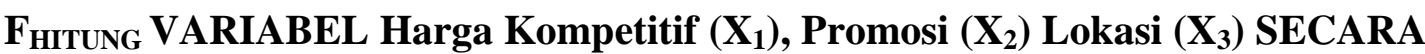

BERSAM-SAMA TERHADAP Keputusan Pembelian

ANOVA $^{\text {b }}$

\begin{tabular}{|c|r|r|r|r|r|}
\hline Model & Sum of Squares & df & Mean Square & F & Sig. \\
\hline Regression & 558.221 & 3 & 186.074 & 251.5 & $.000^{\mathrm{a}}$ \\
& & & & 09 & \\
Residual & 70.284 & 95 & .740 & & \\
Total & 628.505 & 98 & & & \\
\hline
\end{tabular}

Sumber : SPSS Versi 21

Berdasarkan pada tabel 10 tersebut diatas, bahwa terdapat output SPSS Versi 21 dari hasil pengolahan data, dan dari hasil tersebut akan dibandingan dengan probabilitas $F_{\text {tabel }}$ dari taraf signifikan $\alpha(0.00)$. $F_{\text {hitung }}(251.509)>F_{\text {tabel }}(2,70)$.

Adapun hasil pada tabel 10 tersebut diatas, maka dilanjutkan dengan perbandingan antara $\mathrm{F}_{\text {hitung }}$ dan $\mathrm{F}_{\text {tabel }}$ yaitu:

1. Perbandingan $F_{\text {hitung }}(251.509)>F_{\text {tabel }}(2,70)$

2. Perbandingan Nilai Sign $(0,000)<(0,05)$

Berdasarkan hasil analisis perbandingan dapat kita simpulkan bahwa hasil perbandingan tersebut menyatakan dengan jelas $\mathrm{H}_{0}$ ditolak dan $\mathrm{H}_{4}$ diterima demikian juga jika menggunakan nilai signifikan sebesar 0,000. Hal ini menunjukkan bahwa secara bersama-sama variabel harga kompetitif $\left(\mathrm{X}_{1}\right)$, promosi $\left(\mathrm{X}_{2}\right)$ lokasi $\left(\mathrm{X}_{3}\right)$ berpengaruh signifikan dan positif terhadap keputusan pembelian pada konsumen CV Integrity Pangakalpinang.

\section{PENUTUPAN}

\section{Kesimpulan}

Beberapa hal yang disimpulkan dalam penelitian dari hasil pembahsan ini terdapat temuan mengenai Harga kompetitif $\left(\mathrm{X}_{1}\right)$, Promosi $\left(\mathrm{X}_{2}\right)$ Lokasi $\left(\mathrm{X}_{3}\right)$ terhadap keputusan pembelian pada konsumen CV Integrity Pangakalpinang, dapat diuraikan sebagai berikaut :Berdasarkan pengujian secara simultan, ternyata hasil penelitian membuktikan bahwa semua variabel independen (harga kompetitif, promosi dan lokasi) secara simultan 
mempunyai pengaruh yang signifikan terhadap variabel dependen yaitu keputusan pembelian di CV Integrity

1. Berdasarkan analisis secara parsial, hasil penelitian membuktikan bahwa variabel independen (harga kompetitif) mempunyai pengaruh yang signifikan terhadap variabel dependen yaitu keputusan pembelian di CV Integrity

\section{Saran}

Berdasarkan kesimpulan-kesimpulan atas hasil penelitian, maka penulis menyarankan agar bermafaat bagi CV Integrity Pangkalpianang. Adapun saran tersebut adalah sebagai berikut:

1. Sebaiknya CV Integrity lebih memperhatikan tempat agar lebih representatif ketika konsumen datang untuk membeli produk

2 Sebaiknya CV Integrity lebih meningkatkan lagi promosi lewat media elektronik agar dapat memperkenalkan produk dan desain kepada konsumen .

3. Sebaiknya CV Integrity lebih memperhatikan harga produk agar lebih terjangkau oleh konsumen dan bisa bersaing dengan percetakan yang lain.

4. Untuk peneliti selanjutnya disarankan agar menambah variabel lain untuk diteliti sehingga lebih dapat menjelaskan apa saja yang mempengaruhi variabel dependennya.

\section{DAFTAR PUSTAKA}

Arikunto, Suharsimi. 2006. Prosedur Penelitian Suatu Pendekatan Praktik.Jakarta : Rineka Cipta

Arnould, Price \& Zinkhan. 2008. Consumers. Yogyakarta : Andy Offset

Buchari, Alma. 2011. Manajemen Pemasaran dan Pemasaran Jasa. Bandung : Alfabeta.

Charles Lamb, W.et.al. 2001. Pemasaran. Edisi Pertama, Salemba Empat : Jakarta

Cravens, D.W. 2000. Pemasaran Strategis. (terjemahan). Jakarta: Penerbit Erlangga

David, Fred R.2006. Manajemen Strategi Konsep. Jakarta:Salemba Empat

Engel, Blackwell, Miniard, 2012. Perilaku Konsumen. Tangerang: Binarupa Aksara

Ghozali, Imam. 2006. Aplikasi Analisis Multivariate Dengan Program SPSS. Semarang: Badan Penerbit Universitas Diponegoro

Griffin, Jill. 2005. Customer Loyalty: Menumbuhkan \& Mempertahankan Kesetiaan Pelanggan. Jakarta : Erlangga.

Jefkins Frank, 2007. Periklanan. Jakarta : Erlangga.

Kasmir dan Jaffar, 2007. Studi Kelayakan Bisnis. Jakarta:Kencana Prenada Media Grup 
Kotler Philip, 2007. Manajemen Pemasaran. Edisi Millenium, Jilid 1, Jakarta : PT Prenhallindo

Kotler Philip, 2008. Manajemen Pemasaran. Edisi Millenium, Jilid 2, Jakarta : PT Prenhallindo

Kotler Philip dan Gary Amstrong, 2009. Prinsip-Prinsip Pemasaran. Jakarta:Erlangga,

Noviandri, 2010. Kualitas Produk : Alat Strategi Yang Penting. Jakarta:Erlangga

Nugroho J Setiadi. 2003. Perilaku Konsumen. Jakarta : PT Kencana.

Payne, Adrial, 2010. Pemasaran Jasa. Edisi 1. Yogyakarta:Andi Offset.

Ramdani, 2010. Manajemen Jasa. Jakarta : Ghalia Indonesia

Rhenald, 2005. Manajemen Periklanan: Konsep dan Aplikasinya di Indonesia. Jakarta : PAU Ekonomi UI

Robbin dan Coulter, John. 2001. Perilakun Konsumen. Jilid 1 Edisi ke 5. Jakarta : Erlangga.

Siagian, D., dan Sugiarto, 2006, Metode Statistika, Jakarta : Gramedia Pustaka Utama

Shimp Terence A., 2007. Periklanan Promosi. Edisi V, Jilid 1\&2, Jakarta : Erlangga

Sugiyono, 2007. Metode Penelitian Bisnis. Bandung, Alfabeta.

Sugiyono, 2010. Metode Penelitian Bisnis. Bandung, Alfabeta.

Sumarwan, U.,2003. Riset Pemasaran dan Konsumen. Bogor : IPB Press.

Supriyadi, 2004. Riset Pemasaran dan Perilaku Konsumen. Jakarta : Gramedia.

Susanto, 2011. Pengantar Manajemen. Bandung : Bumi Aksara

Swastha Basu dan T. Hani Handoko. 2008. Manajemen Pemasaran Perilaku Konsumen. Edisi 3, Yogyakarta : Liberty.

Swastha Basu dan Irawan, 2009. Manajemen Pemasaran Modern. Yogyakarta : Liberty

Tjiptono Fandy, 2007. Strategi Pemasaran. Yogyakarta, Andy Offset.

Tjiptono Fandy, 2008. Strategi Pemasaran. Yogyakarta, Andy Offset.

Umar, Husen. 2002. Metode Riset Bisnis. Jakarta : PT Gramedia Pustaka Utama.

Wilkie, William L. 2008. Perilaku Konsumen. Yogyakarta : Liberty

William J Stanton, 1996. Prinsip Pemasaran. Jilid I, Edisi 7, Jakarta : Erlangga.

Walker, Jr., Boyd, Jr. Mullins. 2008. Marketing Management. Jakarta : Erlangga 